УДК 616.611-002-036.12+616.24-007.271]-08-035-092

DOI: 10.26435/UC.V0I1(30).219

\author{
Г.А. Игнатенко ${ }^{1}$, И.В. Мухин ${ }^{1}$, В.Г. Гавриляк ${ }^{3}$, Е.Н. Чеботарева ${ }^{2}$, \\ А.С. Дзюбан ${ }^{2}$, Н.Ю. Паниева ${ }^{1}$, Д.С. Паниев ${ }^{1}$ \\ ${ }^{1}$ ГОО ВПО «Донецкий национальный медицинский университет имени М. Горького», Донецк \\ ${ }^{2}$ Донецкое клиническое территориальное медицинское объединение, Донецк \\ ЗФГБУ «1472 Военно-морской клинический госпиталь» МО РФ, Крым, Российская Федерация
}

\title{
ГИПОКСИ-ГИПЕРОКСИТЕРАПИЯ В ЛЕЧЕНИИ БОЛЬНЫХ КОМОРБИДНОЙ КАРДИАЛЬНОЙ ПАТОЛОГИЕЙ
}

Проблема коморбидности/мультиморбидности является доминирующей в современной клинической кардиологии [7]. Стабильная стенокардия (СС) и гипертоническая болезнь (ГБ) являются составляющими самой частой коморбидности у кардиологического контингента больных и по разным оценкам достигает 60-80\% [5].

Однако на сегодняшний день большинство исследований носят преимущественно мононозо-логический характер, что не позволяет в полной мере проанализировать факторы риска, прогнозы развития какой-либо одной нозологии, эффективно решать вопросы их профилактики и лечения [1].

Продолжаются поиски новых направлений медикаментозного и немедикаментозного лечения такой патологии. Одним из компонентов комплексной лечебно-профилактической терапии является уже известная и хорошо зарекомендовавшая интервальная нормобарическая гипокситерапия (ИНБГТ), обладающая комплексом позитивных противоишемических свойств [2-3]. В последние годы дальнейшее ее развитие и совершенствование привело к созданию гипокси-гиперокситерапии (ГГТ), выгодно отличающейся от ИНБГТ [6-7].

Цель исследования заключалась в сравнительном анализе влияния нескольких терапевтических направлений (традиционного медикаментозного, традиционного с метаболитопропными средствами в липосомальной форме, традиционного и липосомального с ИНБГТ и традиционного и липосомального с ГГТ) на клинические параметры ишемическо-гипертензивного синдрома у гипертензивных больных СС.

\section{МАТЕРИАЛ И МЕТОДЫ}

В исследование включено 219 больных СС и ГБ, которые были ознакомлены с дизайном, целью, задачами, длительностью исследования, частотой визитов и после получения соответству- ющих разъяснений и ответов на вопросы, добровольно подписали информированное согласие на участие в проекте. Исследование проводилось в рамках научно-исследовательских тем кафедры пропедевтической и внутренней медицины ГООВПО «Донецкий национальный медицинский университет им. М. Горького» «Применение интервальной нормобарической гипокситерапии в комплексном лечении моноорганной и сочетанной терапевтической патологии», «Разработка, патогенетическое обоснование и внедрение методов липосомальной и адаптационной терапии в комплексном лечении мононозологической и мультинозологической терапевтической патологии», а также комплексированной темы «Разработка и оптимизация методов органопротекции при заболеваниях сердечнососудистой и бронхолегочной системы и их сочетании» с 2009 по 2018 годы.

Критерии включения: возраст больных и здоровых от 42 до 56 лет, эссенциальный характер гипертензивного синдрома, ГБ 1-2 стадии и 1-3 степени, СС 1-2 функциональных классов, хроническая сердечная недостаточность 1-2А стадии (по Василенко-Стражеско).

Верификацию СС и установление ее функционального класса осуществляли посредством холтеровского кардиомониторирования с лестничными пробами (кардиомониторы «Cardio Tens», «Meditech», Венгрия и «Кардиотехника»04-АД-3(М), «Incart», Россия); велоэргометрии (велоэргометр «Ergometrics 900», «Jaeger», Германия), и/или (по показаниям) чреспищеводной электрокардиостимуляции (стимулятор "Servocard SC 100 T-Hellige”, Германия).

Методом случайной выборки больные были

(ㄷ Г.А. Игнатенко, И.В. Мухин, В.Г. Гавриляк, Е.Н. Чеботарева, А.С. Дзюбан, Н.Ю. Паниева, Д.С. Паниев, 2019

(c) Университетская Клиника, 2019 
рандомизированы в 4 статистически гомогенные группы наблюдения, которые не различались между собой по полу $\left(\chi^{2}=0,7, \mathrm{p}=0,3 ; \chi^{2}=1,9\right.$, $\left.\mathrm{p}=0,08 ; \chi^{2}=0,1, \mathrm{p}=0,9 ; \chi^{2}=1,1, \mathrm{p}=0,09\right)$, возрасту $(\mathrm{t}=0,7, \mathrm{p}=0,2 ; \mathrm{t}=1,1, \mathrm{p}=0,13 ; \mathrm{t}=1,3, \mathrm{p}=0,09 ; \mathrm{t}=0,5$, $\mathrm{p}=1,8)$, продолжительности $(\mathrm{t}=1,8, \mathrm{p}=0,06 ; \mathrm{t}=0,3$, $\mathrm{p}=0,6 ; \mathrm{t}=0,5, \mathrm{p}=0,4 ; \mathrm{t}=0,1, \mathrm{p}=0,8)$ и клиническим проявлениям стенокардитического и гипертензивного синдромов $\left(\chi^{2}=1,4, \mathrm{p}=0,08 ; \chi^{2}=0,9, \mathrm{p}=0,2\right.$; $\left.\chi^{2}=0,5, \mathrm{p}=0,2 ; \chi^{2}=1,8, \mathrm{p}=0,06\right)$.

В 1-ю группу наблюдения включены пациенты, которые получали только традиционное медикаментозное лечение гипертензивного и ишемического синдромов, предписанное действующими стандартами.

Пациенты 2-ой группы в дополнении к аналогичной терапии получали липосомальные препараты как компонент противоишемической/антигипоксической терапии. «Липин» (липосомальный фосфатидилхолин) по 0,5 г внутривенно капельно утром на 50 мл физиологического раствора хлорида натрия. «Липофлавон» (27,5 мг липосомального лецитина-стандарта и 0,75 мг кверцетина вечером) внутривенно вече- ром (производственное объединение «Биолек», Харьков, Украина). В дополнении 0,5 г «Липина» вводили ингаляционно при помощи ультразвукового небулайзера. Базовый курс лечения составил 10 дней. В последующем аналогичные курсы липосомального лечения проводились 4 раза в год по 10 дней каждый.

3-ей группе наблюдения проводилась как стандартная, так и липосомальная терапия, но в сопровождении с сеансами ИНБГТ в режиме 5x5x5 (универсальный гипокси-гипероксикатор «Тибет-4», «Newlife», Россия-США).

4-ой группе наблюдения проводилась как стандартная, так и липосомальная терапия, но в сопровождении с сеансами ГГТ (универсальный гипокси-гипероксикатор «Тибет-4», «Newlife», Россия-США). Использовали модифицированную методику Глазачева О.С. [2-3]. Процедуры ГГТ начинали с подачи через маску гипоксической смеси с 11\% концентрацией кислорода (5-7 минут), затем 2-3 минуты подавали гипероксическую газовую смесь с 30\% (до 40\%) кислорода. Длительность гипоксического воздействия и последующей гипероксии зависела от индиви-

Динамика основных клинических показателей

Таблица.

\begin{tabular}{|c|c|c|c|c|c|}
\hline \multirow{2}{*}{$\begin{array}{c}\text { Основные клинические } \\
\text { показатели }\end{array}$} & \multirow{2}{*}{ Этапы } & \multicolumn{4}{|c|}{ Группы больных } \\
\hline & & $\begin{array}{c}\text { 1-я группа } \\
(\mathrm{n}=73)\end{array}$ & $\begin{array}{c}2 \text { 2-я группа } \\
(\mathrm{n}=72)\end{array}$ & $\begin{array}{c}\text { 3-я группа } \\
(\mathrm{n}=74)\end{array}$ & $\begin{array}{c}\text { 4-я группа } \\
(\mathrm{n}=71)\end{array}$ \\
\hline \multirow{2}{*}{$\begin{array}{l}\text { Частота приступов стенокардии } \\
\text { за сутки }\end{array}$} & I & $3,1 \pm 0,05$ & $3,0 \pm 0,03$ & $3,2 \pm 0,05$ & $3,1 \pm 0,08$ \\
\hline & II & $2,9 \pm 0,09$ & $2,6 \pm 0,07$ & $2,1 \pm 0,06^{3,7}$ & $1,5 \pm 0,04^{3,5,6,7}$ \\
\hline \multirow{2}{*}{$\begin{array}{l}\text { Частота безболевой ишемии } \\
\text { миокарда за сутки }\end{array}$} & I & $6,7 \pm 0,07$ & $6,8 \pm 0,06$ & $6,9 \pm 0,07$ & $6,7 \pm 0,07$ \\
\hline & II & $6,4 \pm 0,08$ & $6,0 \pm 0,05$ & $4,8 \pm 0,06^{2,4,7}$ & $3,6 \pm 0,10^{3,5,6,7}$ \\
\hline \multirow{2}{*}{$\begin{array}{l}\text { Частота желудочковой } \\
\text { экстрасистолии, \% }\end{array}$} & I & $24(32,9 \%)$ & $25(34,7 \%)$ & $23(31,1 \%)$ & $26(36,6 \%)$ \\
\hline & II & $17(23,3 \%)^{7}$ & $13(18,1 \%)^{1,7}$ & $12(16,2 \%)^{2,7}$ & $7(9,9 \%)^{3,5,6,7}$ \\
\hline \multirow{2}{*}{$\begin{array}{l}\text { Частота неэффективности } \\
\text { нитратов, \% }\end{array}$} & I & $12(16,4 \%)$ & $15(20,8 \%)$ & $12(16,2 \%)$ & $13(18,3 \%)$ \\
\hline & II & $34(46,6 \%)^{7}$ & $35(48,6 \%)^{7}$ & $27(36,5 \%)^{2,4,7}$ & $20(28,2 \%)^{3,5,6,7}$ \\
\hline \multirow{2}{*}{$\begin{array}{l}\text { Частота достижения целевых } \\
\text { значений АД, \% }\end{array}$} & I & $7(9,6 \%)$ & $8(11,1 \%)$ & $9(12,2 \%)$ & $6(8,5 \%)$ \\
\hline & II & $29(39,7 \%)^{7}$ & $30(41,7 \%)^{7}$ & $37(50,0 \%)^{2,4,7}$ & $45(63,4 \%)^{3,5,6,7}$ \\
\hline \multirow{2}{*}{$\begin{array}{l}\text { Частота физиологических ти- } \\
\text { пов суточной вариабельности } \\
\text { артериального давления, \% }\end{array}$} & I & $5(6,8 \%)$ & $6(8,3 \%)$ & $5(6,8 \%)$ & $5(7,0 \%)$ \\
\hline & II & $19(20,0 \%)^{7}$ & $20(27,8 \%)^{7}$ & $28(37,8 \%)^{2,4,7}$ & $36(50,7 \%)^{3,5,6,7}$ \\
\hline
\end{tabular}

Примечания: I - обследование до лечения, II - обследование через год; 1 - различия между аналогичными показателями в 1-ой и 2-ой группах статистически значимы; 2 - различия между аналогичными показателями в 1-ой и 3-ей группах статистически значимы; 3 - различия между аналогичными показателями в 1-ой и 4-ой группах статистически значимы; 4 - различия между аналогичными показателями во 2-ой и 3-ей группах статистически значимы; 5 - различия между аналогичными показателями во 2-ой и 4-ой группах статистически значимы; 6 различия между аналогичными показателями в 3-ей и 4-ой группах статистически значимы; 7 - различия между аналогичными показателями на 1-м и 2-м этапах наблюдения статистически значимы. 
дуальной гипоксической чувствительности пациента к гипоксии, а переключение между режимами гипокси-гиперокси осуществлялось автоматически по специальным алгоритмам [8].

Клинико-лабораторные показатели оценивали до начала лечения и через год. В течение этого времени пациенты получали суммарно 4 курса ИНБГТ или ГГТ (1 раз в квартал) вместе с липосомальными препаратами.

Для измерения средних суточных значений систолического и диастолического артериального давления (АД) пользовались кардиомониторами «Кардиотехника» - 04-АД-3 фирмы «Incart», Россия и «CardioTens» фирмы «Meditech», Венгрия.

Статистическую обработку результатов выполняли при помощи программы Statistica v. 6 (StatSoft, США). Табличные данные представлены в виде средней (M) и ее ошибки (m). Нормальность распределения анализировали в тесте Колмогоров-Смирнова. Исследуемые параметры имели нормальное распределение, поэтому в расчетах использовали критерий $\mathrm{t}$ для зависимых/независимых выборок. Минимальный уровень значимости, при котором отвергалась нулевая гипотеза, был < 0,05.

\section{РЕЗУЛЬТАТЫ И ОБСУЖДЕНИЕ}

Нами проанализированы клинические параметры течения ишемическо-гипертензивного синдрома (см. табл.). Частота ежесуточных болевых приступов стенокардии в группах больных при исходном исследовании составила 3 приступа, однако частота безболевых состояний по данным холтеровского кардиомониторирования двукратно превосходила частоту болевых эпизодов (6,7/сутки). Таким образом, у больных СС и ГБ имеет место как болевые (классические), так и безболевые (неклассические) эпизоды, зарегистрированные по результатам кардиомониторирования [4]. Относительно влияния разных режимов лечения на частоту болевых и не болевых эпизодов, были получены разные результаты. Так, в 1-ой группе при использовании только традиционного лечения, их частота имела тенденцию к снижению. Аналогичная направленность имела место во 2-ой группе наблюдения. Только в 3-ей группе по результатам лечения через год были получены статистически значимые различия частоты приступов стенокардии с разницей 1,1, а в 4-ой группе - 1,6 за сутки. Относительно влияния лечения на частоту безболевой ишемии миокарда, то статистически достоверные различия зарегистрированы только в 3-ей и 4-ой группах, а различия до и после лечения в них же составили 2,1 и 3,1 соотвественно. Различия между группами 3 и 4 были статистиче- ски значимыми, а величина разницы на 2-м этапе составила 0,6 и 1,2 соотвественно.

При использовании ГГТ эффективность ИНБГТ удалось повысить чередованием коротких гипоксических экспозиций гипероксическими «импульсами» [9]. В экспериментальных работах показано, что в курсе процедур комбинации периодов умеренной гипоксии и гипероксии, эффективность адаптации к миокардиальной ишемии повышается за счет повышения интенсивности редокс-сигнала без углубления гипоксии, а режим тренировки «гипоксия/гипероксия» более эффективно предупреждает развитие АФК-индуцированные, стрессорные нарушения и увеличивает физическую выносливость животных по сравнению с режимом «гипоксия/ нормоксия» при ИНБГТ [11-12]. Причем тренирующие эффекты ГГТ в режиме «гипоксия/гипероксия» развиваются быстрее по сравнению с традиционной методикой ИНБГТ [13].

Основным механизмом позитивного влияния ГГТ является стимуляция опосредованной активацией гипоксия-индуцированного фактора 1 и других сигнальных молекул экспрессии генов, которые отвечают за синтез эритропоэтина, эндотелиального фактора роста, моноксида азота (важно с позиции системной и локальной вазодилатации, понижения системного давления) и других транскрипционных факторов, инициирующих множественные внутриклеточные, органные и системные эффекты $[14,18]$. Наше внимание привлекла возможность повышения эффективности гипокситерапии чередованием коротких гипоксических экспозиций не нормоксическими, а гипероксическими интервалами в 4-ой группе наблюдения, подавая в эти периоды пациенту через маску газовую смесь с содержанием кислорода - 30, иногда 40\%. Известно, что одним из ключевых механизмов запуска адаптивных ответов организма на гипоксию является индукция активных форм кислорода, инициирующие транскрипцию многих регуляторных факторов: процессы антиоксидантной защиты, противовоспалительный потенциал, эффективность утилизации кислорода митохондриями и пр. $[15,17]$. Совмещение гипоксических и гипероксических (вместо нормоксических, как при ИНБГТ) эпизодов при тренировке позволит усилить синтез активных форм кислорода индуцируемый сигнал без углубления гипоксии. Применение такого режима в сравнении с традиционными ИНБГТ оказывает более выраженные мембраносохраняющие эффекты, более существенно и оперативно повышает стрессорную и гипоксическую устойчивость миокарда, почек и мозга, повышает мощность антиоксидантных защитных механизмов [16]. 
Желудочковые нарушения ритма в подавляющем числе случаев были представлены различной степенью тяжести желудочковой экстрасистолии. В подавляющем числе случаев желудочковая экстрасистолия была зависима от состояния коронарного кровотока, т.е. носила вторичный (ишемический) характер. Во всех группах были получены статистически достоверные различия до и после лечения $(9,6 ; 16,6 ; 14,9$ и $26,6 \%)$.

Нитратная толерантность является одним из краеугольных камней терапии СС и с течением времени ее частота только увеличивалась, практически пропорционально во всех группах - на 30,2; 27,8; 37,8 и 9,9; соотвественно. Следует отметить, что при ГГТ состояние нитратной толерантности было статистически достоверно меньшим, чем при использовании других методик, в том числе и ИНБГТ.

Частота достижения целевых цифр давления в группах на 2-м этапе лечения составила 39,7 ; 41,$7 ; 50,0$ и 63,4\%. При этом различия между 1-ой и 2-ой группами отсутствовали. Наблюдается существенный прирост данного показателя при использовании методик гипокситерапии с преобладанием ГГТ.

Частота физиологических колебаний артериального давления в группах больных составила 20,$0 ; 27,8 ; 37,8$ и 50,7\% соотвественно, а различия до и после лечения - 13,2; 19,5; 31,0 и 43,7\% соотвественно. Из приведенных данных следует, что адаптационные методики способствовали более выраженному приросту частоты физиологических суточных вариантов колебания давления.

Есть основания полагать, что в основе противоишемического влияния гипоксических методик (ИНБГТ и ГГТ) лежит комплекс механизмов, индуцируемых в первом случае тренировкой гипоксия-нормоксия, а во втором - гипоксиягипероксия [3, 6, 9, 16, 18]. При использовании последней достигается двойной эффект, как за счет чередования состояния гипоксиянормоксия, так и за счет дополнительной импрегнации кислорода в условиях повышенного парциального давления. По мнению представленных авторов, основной клинический эффект (противоишемический, антигипертензивный, противоаритмический) реализуется при помощи активации синтеза оксида азота. Сказанное особенно явственно продемонстрировано на обратимости частоты безболевой ишемии миокарда, оптимальном снижении артериального давления и возвращении его суточных колебаний к физиологическим (типы dipper или non dipper). Именно восстановление секреции/ высвобождения/чувствительности NO является главным физиологическим механизмом, противостоящим комплексу патофизиологических механизмов. Вполне понятно, что многие механизмы в этом случае потенциально обратимы. В тех же случаях, когда в основе лежат необратимые (органические) изменения (кальцинированная атеросклеротическая бляшка, фиброз, воспаление) такие методы во многом оказываются неэффективными как при использовании медикаментозных, так и гипоксических методик.

\section{В Ы В 0 д Ы}

1. У больных сочетанной кардиальной патологией установлен смешанный характер ишемических проявлений (классических приступов стенокардии и безболевой ишемии миокарда), с двукратным преобладанием безболевых эпизодов над болевыми приступами.

2. Традиционное лечение и аналогичное с липосомальными препаратами фосфатидилхолина/кверцетина практически не оказывало влияния на частоту безболевых эпизодов ишемии. Антиангинальный эффект «гипоксических» методик (ИНБГТ и ГГТ) проявлялся как существенным урежением стенокардитических приступов, так и частоты безболевой ишемии миокарда, что достигалось влиянием преимущественно на потенциально обратимые механизмы, лежащие в основе ангинального синдрома.

3. Желудочковая экстрасистолия в условиях кардиальной коморбидности встречалась у каждого 3-4 пациента и носила вторичный характер, зависимый от выраженности ишемии. Эффективность влияния лечения на частоту желудочковой экстрасистолии у представителей 2-ой и 3-ей группы были практически идентичными, в то время как в 4-ой группе она была максимальной среди всех режимов лечения.

4. Нитратная толерантность на фоне лечения с использованием традиционных медикаментозных методов и с добавлением липосомальных форм фосфатидилхолина/кверцетина возросла в 2 раза по сравнению с исходными значениями. Частота неэффективности нитратов у представителей 3-ей группы была статистически меньшей, чем в 1-ой и 2-ой. Частота нитратной толерантности была наименьшей на 2-м этапе лечения при использовании методики ГГТ.

5. Исходные показатели достижения целевого уровня давления в группах наблюдения не превышали 12\%. Если на фоне годичного лечения в 1-ой и 2-ой группах частота достижения оптимального уровня давления составила всего $40 \%$, то на фоне ИНБГТ больше - до 50\%, а с использованием методики ГГТ - до 63,4\%. Исполь- 
зование гипоксических методик в комплексном лечении гипертензивного синдрома позволяет потенцировать антигипертензивный эффект базисной медикаментозной терапии.

6. Частота оптимальных (физиологических) типов суточной вариабельности артериального давления у представителей 3-ей группы статистически значимо превосходила результаты лечения в 1-ой и 2-ой группах, но максимальное значение показателя было достигнуто в 4-ой группе (50,7\%) при использовании методики ГГТ.

\section{Г.А. Игнатенко ${ }^{1}$, И.В. Мухин ${ }^{1}$ В.Г. Гавриляк ${ }^{3}$, Е.Н. Чеботарева ${ }^{2}$, А.С. Дзюбан ${ }^{2}$, Н.Ю. Паниева ${ }^{1}$, Д.С. Паниев ${ }^{1}$}

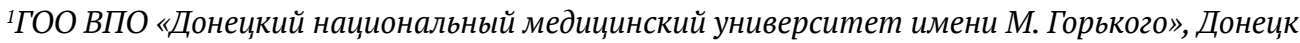

${ }^{2}$ Донецкое клиническое территориальное медицинское объединение, Донецк

${ }^{3}$ ФББУ «1472 Военно-морской клинический госпиталь» МО РФ, Крым, Российская Федерация

\section{ГИПОКСИ-ГИПЕРОКСИТЕРАПИЯ В ЛЕЧЕНИИ БОЛЬНЫХ КОМОРБИДНОЙ КАРДИАЛЬНОЙ ПАТОЛОГИЕЙ}

Применение гипокси-гиперокситерапии в комплексе лечебных мероприятий при сочетанной кардиальной патологии у гипертензивных больных стенокардией напряжения позволяет получить дополнительный противоишемический эффект как по влиянию на болевые, так и в большей степени на безболевые эпизоды, значительно снизить частоту ишемиязависимых желудочковых нарушений ритма, более эффективно тормозить формирование нитратной толерантности и достичь более значимых показателей достижения целевых значений артериального давления и его физиологических суточных колебаний по сравнению с другими методами лечения.

Ключевые слова: гипокси-гиперокситерапия, лечение, коморбидная кардиальная патология.

\section{G.A. Ignatenko', I.V. Mukhi ${ }^{1}$, V.G. Gavrilyak ${ }^{3}$, E.N. Chebotareva ${ }^{2}$, A.S. Dzuban ${ }^{2}$, N.Yu. Panieva ${ }^{1}$, D.S. Paniev ${ }^{1}$}

${ }^{1}$ SEI HPE «M. Gorky Donetsk National Medical University», Donetsk

${ }^{2}$ Donetsk clinical territorial medical association

${ }^{3} 1472$ Naval Clinical Hospital MD RF, Crimea, Russia

\section{HYPOXIA HYPEROXITHERAPY IN THE TREATMENT OF PATIENTS WITH COMORBID CARDIAC PATHOLOGY}

The use of hypoxia hyperoxitherapy in complex of therapeutic measures in combined cardiac pathology in hypertensive patients with angina provides additional anti-ischemic effect as the effect on pain, and to greater extent on no pain episodes, reduce the frequency of ischemia-dependent ventricular arrhythmias, more effective- ly inhibit the formation of nitrate tolerance and attain higher levels of achievement of target blood pressure values and physiological daily fluctuations.

Key words: hypoxia hyperoxitherapy, treatment, comorbid cardiac pathology.

\section{ЛИТЕРАТУРА}

1. Митьковская Н.П., Патеюк И.В., Статкевич Т.В. и др. Безболевая ишемия миокарда у пациентов с метаболическим синдромом: стратификация кардиоваскулярного риска. Новости медико-биологических наук. 2015; 3: 39-42.

2. Глазачев О. С. Технологии коррекции психофизиологических функции и повышения резерва человека: реализация принципов адаптационной медицины. Вестник международной академии наук. 2013; 1: 45-54.

3. Глазачев О. С. Оптимизация применения интервальных гипоксических тренировок в клинической практике. Медицинская техника. 2013; 3(279): 21-24.

4. Лямина Н.П., Карпова Е.С., Котельникова Е.В. Маркёры ишемии миокарда: патофизиологическое обоснование клинического применения. Патогенез. 2018; 1 : 17-26.

5. Николаев Ю.А., Митрофанов И.М., Поспелова Т.И. и др. Особенности полиморбидности в современной клинике внутренних болезней. Бюллетень СО РАМН. 2014; 2: 44-49.

6. Гогаева Е.К., Лазоришинец В.В., Дзахоева Л.С., Писарев

\section{REFERENCES}

1. Mit'kovskaya N.P., Pateyuk I.V., Statkevich T.V. i dr. Bezbolevaya ishemiya miokarda u pacientov s metabolicheskim sindromom: stratifikaciya kardiovaskulyarnogo riska. Novosti mediko-biologicheskih nauk. 2015; 3: 39-42. [in Russian]

2. Glazachev O.S. Tekhnologii korrekcii psihofiziologicheskih funkcii i povysheniya rezerva cheloveka: realizaciya principov adaptacionnoj mediciny. Vestnik mezhdunarodnoj akademii nauk. 2013; 1: 45-54. [in Russian]

3. Glazachev O. S. Optimizaciya primeneniya interval'nyh gipoksicheskih trenirovok vklinicheskoj praktike. Medicinskaya tekhnika. 2013; 3(279): 21-24. [in Russian]

4. Lyamina N.P., Karpova E.S., Kotel'nikova E.V. Markyory ishemii miokarda: patofiziologicheskoe obosnovanie klinicheskogo primeneniya. Patogenez. 2018; 1: 17-26. [in Russian]

5. Nikolaev YU.A., Mitrofanov I.M., Pospelova T.I. i dr. Osobennosti polimorbidnosti v sovremennoj klinike vnutrennih boleznej. Byulleten' SO RAMN. 2014; 2: 44-49. [in Russian]

6. Gogaeva E.K., Lazorishinec V.V., Dzahoeva L.S., Pisarev 
А.Н. Первый опыт использования гипоксигиперокситерапии. Вісник серцево-судинної хірургії. 2016; 3: 1419.

7. Тарловская Е. И. Проблема полиморбидности - вызов современной медицине. Терапия. 2017; 2: 4-14.

8. Юпатов Г.И., Доценко Э.А., Юпатов Ю.Г. Применение технологий гипобароадаптации в клинике внутренних болезней (Обзор литературы). Вестник Витебского государственного медицинского университета. 2013; 4: 7-18.

9. Syrkin A. L., Glazachev O. S., Kopylov F. Y. et al. Adaptation to Intermittent Hypoxia-Hyperoxia in the Rehabilitation of Patients With Ischemic Heart Disease: Exercise Tolerance and Ouality of Life. Kardiologiia. 2017; 57 (5): 10-16.

10. Bayer U., Glazachev O. S., Likar R. et al. Adaptation to intermittent hypoxia-hyperoxia improves cognitive performance and exercise tolerance in elderly. Adv. Gerontol. 2017; 30 (2): 255-261.

11. Basovich S. N. Trends in the use of preconditioning to hypoxia for early prevention of future life diseases. Biosci. Trends. 2013; 7(1): 23-32.

12. Bosco G., Verratti V., Fanò G. Performances in extreme environments: effects of hyper/hypobarism and hypogravity on skeletal muscle. European Journal Translational Myology. 2010; 1 (3): 83-90.

13. Cardinale D.A., Ekblom B. Hyperoxia for performance and training. J. Sports Sci. 2018; 36 (13): 1515-1522.

14. Bayer U., Likar R., Pinter G. et al. Intermittent hypoxichyperoxic training on cognitive performance in geriatric patients. Alzheimers Dement. 2017; 3 (1): 114-122.

15. Glazachev O.S., Zvenigorodskaia L.A., Dudnik E.N. et al. Interval hypoxic-hyperoxic training in the treatment of the metabolic syndrome. Eksp. Klin. Gastroenterol. 2010; 7: 51-56.

16. Glazachev O. Optimization of clinical application of interval hypoxic training. Biomed. Eng. 2013; 47(3): 134137.

17. Mallette M.M., Stewart D.G., Cheung S.S. The Effects of Hyperoxia on Sea-Level Exercise Performance, Training, and Recovery: A Meta-Analysis. Sports Med. 2018; 48(1): 153-175.

18. Serebrovskaya T. V. Intermittent hypoxia training as nonpharmacologic therapy for cardiovascular diseases: Practical analysis on methods and equipment. Exp. Biol. Med. 2016; 241(15): 1708-1723.
A.N. Pervyj opyt ispol'zovaniya gipoksigiperoksiterapii. Visnik sercevo-sudinnoï hirurgiï. 2016; 3: 14-19. [in Russian]

7. Tarlovskaya E. I. Problema polimorbidnosti - vyzov sovremennoj medicine. Terapiya. 2017; 2: 4-14. [in Russian]

8. Yupatov G.I., Docenko EH.A., YUpatov YU.G. Primenenie tekhnologij gipobaroadaptacii $\mathrm{v}$ klinike vnutrennih boleznej (Obzor literatury). Vestnik Vitebskogo gosudarstvennogo medicinskogo universiteta. 2013; 4: 7-18. [in Russian]

9. Syrkin A. L., Glazachev O. S., Kopylov F. Y. et al. Adaptation to Intermittent Hypoxia-Hyperoxia in the Rehabilitation of Patients With Ischemic Heart Disease: Exercise Tolerance and Ouality of Life. Kardiologiia. 2017; 57(5): 10-16.

10. Bayer U., Glazachev O. S., Likar R. et al. Adaptation to intermittent hypoxia-hyperoxia improves cognitive performance and exercise tolerance in elderly. Adv. Gerontol. 2017; 30(2): 255-261.

11. Basovich S. N. Trends in the use of preconditioning to hypoxia for early prevention of future life diseases. Biosci. Trends. 2013; 7(1): 23-32.

12. Bosco G., Verratti V., Fanò G. Performances in extreme environments: effects of hyper/hypobarism and hypogravity on skeletal muscle. European Journal Translational Myology. 2010; 1 (3): 83-90.

13. Cardinale D.A., Ekblom B. Hyperoxia for performance and training. J. Sports Sci. 2018; 36(13): 1515-1522.

14. Bayer U., Likar R., Pinter G. et al. Intermittent hypoxichyperoxic training on cognitive performance in geriatric patients. Alzheimers Dement. 2017; 3(1): 114-122.

15. Glazachev O.S., Zvenigorodskaia L.A., Dudnik E.N. et al. Interval hypoxic-hyperoxic training in the treatment of the metabolic syndrome. Eksp. Klin. Gastroenterol. 2010; 7: $51-56$.

16. Glazachev O. Optimization of clinical application of interval hypoxic training. Biomed. Eng. 2013; 47(3): 134137.

17. Mallette M.M., Stewart D.G., Cheung S.S. The Effects of Hyperoxia on Sea-Level Exercise Performance, Training, and Recovery: A Meta-Analysis. Sports Med. 2018; 48(1): $153-175$.

18. Serebrovskaya T. V. Intermittent hypoxia training as nonpharmacologic therapy for cardiovascular diseases: Practical analysis on methods and equipment. Exp. Biol. Med. 2016; 241(15): 1708-1723. 